\title{
THE RELATIONSHIP BETWEEN FIRM INTELLECTUAL CAPITAL AND THE COMPETITIVE ADVANTAGE
}

\author{
*İpek KOÇOĞLU \\ *Salih Zeki İMAMOĞLU \\ *Hüseyin İNCE \\ *Gebze Institute of Technology,
}

\begin{abstract}
Previous studies rarely examined the relationship between intellectual capital and competitive advantage. Most studies underestimate the shift towards knowledge based economy where, capital and work are no longer the differentiating and generating factors of sustainable competitive advantage. Relatively, little is known in the literature about how intellectual capital affects competitive advantage. This study will contribute to the literature by proposing a theoretical model considering the relationship of intellectual capital with the creation of competitive advantage in knowledge intensive organizations. Additionally, the extensive literature review will be utilized in the development of five hypotheses linking intellectual capital with competitive advantage. The hypotheses show that, human capital, organizational capital and relational capital positively influence competitive advantage. Moreover the positive influence of intellectual capital on strategy formulation and the positive influence of strategy formulation on competitive advantage constitute the basis for the hypothesis; intellectual capital positively influences competitive advantage. The last hypothesis is based on the positive influence of innovation on competitive advantage regarding the positive relationship between the relational capital and innovation. A future research opportunity can be the statistical testing of the hypotheses with the survey method.
\end{abstract}

Keywords: Intellectual Capital, Competitive Advantage, Human Capital, Organizational Capital, Relational Capital, Knowledge Based Economy.

\section{INTRODUCTION}

In today's competitive global market, value creating factors for companies are changing. Silvi and Cuganesan (2006) refer to Eustace's statement saying, "a fundamental shift in the corporate value system, away from physical and financial assets towards the creative exploitation of a nexus of intangible assets, quasi-assets and competences - mainly in the form of distinctive capabilities deriving from knowledge intangibles" (Silvi and Cuganesan, 2006). Competition is forcing many companies to accumulate intellectual assets and to seek to use them effectively to produce profitable actions (Bismuth and Tojo, 2008). "Information society", "knowledge society", and "knowledge economy" are some of the concepts that were coined in the twentieth century to highlight the role of knowledge as the critical and differentiating key of economic growth (Lavanderos, 2008). On the opposite of other primary resources, knowledge does not diminish as it is used, instead it gets depth 
as it is used and shared. Consequently knowledge intensive firms rely on the management of the knowledge which will be adding value to the knowledge workers, products and interactions (Seetharaman, Saravanan and Teng Low, 2004). When in the transition from 1930's to 1960's the enterprise objective shifted from being profit maximization to value maximization, it has been recognized that the economic and productive capacity of an organization lies more in its intellectual and service capabilities than its hard assets. Regarding this new environment, characterized by increasingly global markets, dynamic, uncertain environment and competitive conditions, companies need to be able to earn economic returns from intellectual assets, accordingly intellectual capital is becoming a crucial factor for a firm's long-term profit and performance in the knowledge-based economy as more and more firms identify their core competence as invisible assets rather than visible assets (Bismuth and Tojo, 2008; Hsu and Fang, 2008). Capital and work are no longer the differentiating and generating factors of sustainable competitive advantage. As a result intangibles have drawn the attention of companies (Lavanderos, 2008). It is increasingly recognized that the performance of any organization, is substantially dependent upon the knowledge of its employees, the application and integration of that knowledge to the structures of the organization, and its relationships (Silvi and Cuganesan, 2006). Nonaka and Takeuchi focuses on the reality that the future will be constructed on a knowledge-based society in which knowledge storage and application are the basis of economic growth and accumulated capital, additionally in the knowledge-based economy, learning and knowledge are the key parameters of the sustainable competitive advantage function.(Hsu and Fang, 2008; Smith and Hansen, 2002). The organizations cannot create unique values to customers unless it has unique capabilities based on the differentiation rather than operational effectiveness because industries in such a society do not rely on traditional production factors for their competitive advantage, but on knowledge management and integration (Smith and Hansen, 2002; Hsu and Fang, 2008). This trend stresses the importance of intellectual capital as a promoting factor on competitive advantage. Despite the fact that intellectual capital and competitive advantage are so important for the development of firms, few studies focus on how these two factors relate to and trigger each other. Guthrie and Petty (2000) note that works on the framework placing intellectual capital as instrumental in the determination of enterprise value are lacking in the literature. The factor that generates enterprise value is regarded as the competitive advantage of a firm (Guthrie and Petty,2000). Contingently, intellectual capital as the instrumental determinant of enterprise value, using the mediating role of the competitive advantage, constitutes a gap in the literature. Guthrie and Petty (2000) mention the argument of Roos et al. (1997) presenting that intellectual capital can be linked to other disciplines such as corporate strategy. From a strategic perspective, intellectual capital is used to create and use knowledge to enhance firm value (Guthrie and Petty, 2000). The fundamental question is; is it the intellectual capital of the firm that leads to succeed long term, sustainable, unbeatable competitive advantage, in today's global market?

This study will contribute to the literature by proposing a theoretical model considering the relationship of intellectual capital with the creation of competitive advantage in knowledge intensive organizations. The exploratory research question to start with is; "Does intellectual capital provides the achievement of sustainable competitive advantage in today's globally competitive market of knowledge-based economy?" The main purpose of this study is to explore the intellectual capital, rather than the traditional tangible assets -land, facility, work force, physical and financial capitalconsidered as capital, in depth as a crucial factor creating the competitive advantage for the organizations in turbulent markets, shifting towards dynamic nature and mainly from production based to the knowledge based economy. In addition to examining the relationship between firm intellectual capital and competitive advantage, this study develops a platform through which 
intellectual capital will shape the vision, mission and strategic management of the organizations. Previous studies rarely examined the connection and relevancy of intellectual capital, and the competitive advantage as an indicator of successful strategic management. Noticing the transformation of firms' main goals from the profit maximization to value maximization, the intellectual capital that assures the creation and management of knowledge became the most important asset of the knowledge based economy, since the knowledge is the creator of value and effective management of knowledge is the factor maximizing value.

\section{Intellectual Capital}

The fact of calling intellectual "capital" makes reference to its economic roots, because it was first described in 1969 by the economist Galbraith as a process of value creation and as a bundle of assets at the same time. The economist Kenneth Galbraith presented intellectual capital as the difference between market value and book value. Consequently, the roots of the intellectual capital in businesses appeared as an application for the aim of understanding what constitutes the value in the business environment to effectively, hence strategically manage the value creating assets in the business environment (Sveiby, 1997; Edvinsson and Malone, 1997; Johansson, 1999). The historical perspective is an essential component in fostering an understanding of the context within which IC came to be viewed as the essential business element that it is today (Guthrie and Petty, 2000). Plenty of arguments have been discussed in the literature regarding the reasons to understand intellectual capital, ranging from the theme that IC matters in Stewart's (1997) work, to recognizing intellectual capital has the potential to improve the efficiency of both capital and labor markets (Guthrie and Petty, 2000).

Intellectual capital, started to be popularized in the business life with Tom Stewart's article titled "Brainpower" which was published in Fortune magazine in 1990's. Stewart, in his article defined intellectual capital as the cumulative collection of al the assets that create value for the organization which provides competitive advantage in the market for the firm (Sullivan, 2000). The term intellectual capital is used as a synonym for intangible or knowledge assets since the work by Stewart (1991).

The works on intelectual capital reflects two separate but consequent periods where intellectual capital evolved from what it was to what it is now. The studies untill the mid 1990's constitute the first period and the studies after this period represent the second period of the intellectual capital research. The first period efforts was focused on the aim of generating the consciousness about intellectual capital and raising the awareness for intellectual capital in creating and managing a sustainable competitive advantage. The publications in this period was gathered under the common subject of "there is a conceptas intellectual capital, it has a critical role and there is need to measure and report it." In the second period, researchers strated to go down to more micro level, meaning that they started to consider intellectual capital from the organization's perspective. This stage has been one of consolidation that established research into IC as a legitimate undertaking and has sought to gather robust evidence in support of its further development. The focus is on the perception of intellectual capital's importance regarding the behavior of labour and capital markets (Guthrie and Petty, 2000). Yet, a further stage appears in today's literature, since now entrepreneurs and business men know the urgency, neccessity and importance of intellectual capital, also know that they hide some value to be brought out in their organization under the shelter of intellectual capital but they don't know how to obtain value out of this capital. The next stage of efforts which this study aslo 
focuses on is the influence of intellectual capital to company performance, including competitive advantage. Tan et al. claims that regarding this stage there is a gap in the literature (Tan et al., 2008).

Consequent to the emergence and acceptance of intellectual capital, the question regarding the urgency of it today arises. Why the implication of intellectual capital, started in recent economic, managerial, technological, and sociological developments whereas it was previously unknown and vastly unforeseen? The reason why intellectual capital becomes crucial for the enterprises, lies behind the changes in the business conditions giving birth to the knowledge-based economy. The revolution in the information technology and information society, the rising importance of knowledge and knowledge-based economy, the changing patterns of interpersonal activities and the network society, the emergence of innovation as the principal determinant of competitiveness, are the factors emphasizing intellectual capital instrumental in the determination of enterprise value (Guthrie and Petty, 2000: 157).

Today, intellectual capital is the subject of increasing research by both academics and practitioners (Petty and Guthrie, 2000). It is also an area of increasing government interest and funding (Tan, Plowman and Hancock, 2008). There are as many definitions as existing researchers dedicated to the development of this subject. Though a universally accepted definition on the intellectual capital is still absent. Kaufmann and Schneider (2004) mentions the claim of Bukh et al. (2001) in his study who states that no unique definition for intellectual capital exists and claims that, "it is a fragile construct, which has to be continuously supported and held together by a whole array of interrelated elements"(Kaufmann and Schneider, 2004). Even if there are other sources of definitions excluded in the study of Kaufmann and Schneider (2004), the authors have identified thirty seven definitions about the intellectual capital. According to Lavanderos (2008); if the other sources which were not included in their study, such as Brooking, Andriessen, Bueno, Viedma, the Meritum Project, the Intellect Club, Allee and Saint Onge are added, there wil be reached over forty five other definitions (Lavanderos, 2008).

\section{Definition of Intellectual Capital}

This study reviews some of the significant extant literature on intellectual capital and displays the definitions of it in a way that provides a useful understanding of what is the concept and movement. As there has not been a solidarity upon a universal intellectual capital definition yet, it's essential to be familiar with all of its definitions for the aim of fully comprehending and drawing a big picture of intellectual capital.

In order to look at it from a broad perspective, first intangible assets need to be understood. The concept of intangible assets constitutes an umbrella above intellectual capital. The definition of an intangible asset can be summarized as "knowledge that can be converted into profit which help organizations generating value and accordingly a claim to future benefits that does not have a physical or financial (a stock or a bond) embodiment" (Lev, 2001: 5; Sullivan, 2000: 5). Firms obtain value from this profit generated from the sale of goods or services, and that firms depend on intangibles such as reputation, customer loyalty, name recognition, leadership, and standard setting, and these are vitally dependent upon human capital to ensure repeat business (Choong, 2008).

Intellectual capital is generally defined as the intellectual material - knowledge, information, intellectual property, experience - that can be put to use to create wealth (Stewart, 1997). The creator of this definition; Stewart (1998) presents intellectual capital as; the sum of all the knowledge that all the employees of a company have - knowledge, information, intellectual property and experience 
base and which can be put to use for the creation wealth, giving it a competitive advantage (Stewart, 1998: 7). Similiarly, Bontis (1998) considers that intellectual capital possesses intellectual attributes that can contribute to the value of a firm (Choong, 2008). Further, Bontis, Dragonetti, Jacobsen and Roos (1999) define intellectual capital as "the quite simple the collection of intangible resources and their flows", intangible resources is "any factor that contributes to the value generating processes of the company" (Kaufmann and Schneider, 2004). Brooking (1997) identifies intellectual capital as "market assets," "human-centered assets," "intellectual property assets," and "infrastructure assets" that when combined with an organization's other productive resources will eventually lead to value creation (Choong, 2008). Choong (2008) discusses, Edvinsson's (1997) presumption similar to that of Brooking's, that intellectual capital is not an objective thing, but is a relationship issue and a debt item, which is borrowed from the customers and employees and only by combining intellectual capital with these items, an organization can become more productive (Choong, 2008). According to International Federation of Accountants (1998) intellectual capital can be thought of as the knowledge-based equity of a company (Tan, Plowman and Hancock, 2008). Choong (2008) also refers to the study of Boudreau and Ramstad (1997) who consider that intellectual capital is closely related to human resource management that is needed by the organization to provide the necessary impetus for future development and growth (Choong, 2008).

Edvinsson and Malone make a metaphor in defining the intellectual capital; a tree, whose life depends on its roots, which are underground. Similiarly, the success of a company depends on its intellectual capital, which is also a hidden resource identified as an intangible. Hence, in their notion of intellectual capital, Edvinsson and Malone (1999) include - among other factors - those of knowledge, skills, inventive, and capacity of the employees to perform their tasks, as well as equipment, programs, databases, trademarks, and relations with customers (Lavanderos, 2008). Davenport and Prusak (1997) relates intellectual capital with technology, technological changes, and things associated with the management of information technology (IT). The ability of an organization that can utilize technology to manage and process information will be the one that has the capability to employ intellectual capital into good use (Choong, 2008).

Rastogi (2003) brings out the description of, "intellectual capital may properly be viewed as the holistic or meta-level capability of an enterprise to co-ordinate, orchestrate, and deploy its knowledge resources towards creating value in pursuit of its future vision" (Kaufmann and Schneider, 2004). A related definition comes from Lev (2001) and Daum (2002) stating that intellectual capital cannot come to appear by itself but it is a result depending upon the interaction of the network effect of other assets and the use of human, organizational, intellectual resources (Kaufmann and Schneider, 2004). Very similarly Mouritsen et al. (2004) indicate that IC mobilizes "things" such as employees, customers, IT, managerial work and knowledge. They add, "IC cannot stand by itself as it merely provides a mechanism that allows the various assets to be bonded together in the productive process of the firm" (Choong, 2008). Lev (2001) moreover claims that an intangible asset is a claim to future wich does not have any physical or financial appearance (Kaufmann and Schneider, 2004). Accounting researcher, Ordones de Pablos (2003), presents the description; "A broad definition of intellectual capital states that it is the difference between the company's market value and its book value. Knowledge based resources that contribute to the sustained competitive advantage of the firm form intellectual capital" (Kaufmann and Schneider, 2004). Non-accounting researchers define "intellectual capital" as the "difference between the firm's market value and its book value of entity" (Edvinsson and Malone, 1997; Stewart, 1997; Sveiby, 1997; Mouritsen et al., 2001). Instead according to accounting researchers, the difference between the market value of the enterprise and the book value of the entity's identifiable assets is defined as "goodwill." Goodwill is also known as 
"intangible assets" (Choong, 2008). Sullivan (2000) indicates intangibles as "knowledge that can be converted into profit." and Lev (2001) claims that "An intangible asset is a claim to future benefits" (Sullivan, 2000: 228; Kaufmann and Schneider, 2004). Lev and some other researchers use the notion of intangibles, though the term intellectual capital is often regarded as synonymous to intangible assets, the definition of OECD makes an appropriate distinction by locating intellectual capital as a subset of intangible assets of an organization. As a support to this distinction between the two concepts, reputation is an item of intangible nature that does not form part of the firm's intellectual capital but may constitute part of its outcome (Guthrie and Petty, 2000). Yet some authors use the two notions as synonymous but there is a consensus in the literature that the intangibles form an umbrella above the intellectual capital concept. Also the distinction between intellectual capital and knowledge management seems unclear, thus knowledge management, as a function, describes the act of managing the intellectual capital (Petty and Guthrie, 2000).

Lvanderos (2008) defines intellectual capital in agreement with the initial notions as the sum of all the knowledge (Stewart, 1998; Sullivan, 2000), which is owned by all the employees of a company and provide this one with a competitive advantage, or to put in other words, it is intellectual material such as knowledge, information, intellectual property and experience (Bontis, 1998), of which companies can take advantage in order to create wealth (Lavanderos, 2008). Andreou et al. (2007, p. 53) state that the business enterprise in this knowledge era has a need to become "intelligent" about its environment to gain knowledge from its environment and subsequently value its intangible resources. They argue that in order for an enterprise to become "intelligent" it is necessary for it to scrutinize its business processes/functions, codify them to facilitate the modeling of business activities, and provide definitions, attributes and constraints of business intelligence that align with the performance of the enterprise (Choong, 2008). Chong (2008) noted the similarities in the definition of intellectual capital by Lev (2001), Daum (2002), Rastogi (2003) and Mouritsen et al. (2004). It appears to have two things in common; the first is that, intangible cannot stand by itself, and hence, it cannot be valued separately from other assets; and the second likeness is that intellectual capital is the result of the network effect of utilizing various intellectual, human, capital and organizational resources. (Choong, 2008).

Further, regarding to all of the definitions presented in this study intellectual capital can be summarized as the accumulation of all information, knowledge, wisdom, experience, social and cultural interactions of an organization - rather than only the employees, internalized through the structural routines, processes, systems (Bontis, Dragonetti, Jacobsen and Roos, 1999; Andreou et al., 2007; Mouritsen et al., 2004) for the aim of creating an "intelligent" organization which generates value and competitive advantage (Petty and Guthrie, 2000; Choo and Bontis, 2002; Edvinsson and Malone, 1997; Ordones de Pablos, 2003; Stewart, 1998) in the market.

\section{Categorization of Intellectual Capital}

Numerous groups, accounting professions and researchers have attempted to categorize intangibles. Categorization enables to order the systematic organization of a magnitude of possibilities into a set of class consisting of a coherent number of items (Choong, 2008). Following the big picture drawn by the definitions in the literature the categorization of the intellectual capital discovering the content and scope of it will serve consistently to the aim of exploring and analyzing "what is in the domain of the intellectual capital which has the potential to create competitive advantage for the organizations?" Choong (2008) states that the categorization indicates a better way in the description of what intellectual capital is, in comparison to using the definition approach. There are two reasons for this. 
First, intellectual capital is "invisible" (it has no physical appearance), that's why it is much harder to define than many other items. Second, the study of intellectual capital is relatively new and evolving, and it is hard to isolate the range of activities associated with it that can be defined (Choong, 2008).

Sveiby was one of the pioneers in this field. But broadened his classification to the categorization of intangibles, which are; employee competence, internal structure, and external structure. External structure concerns customer and supplier relations. Internal structure consists of patents, concepts, computer and administrative systems. The corporate culture of the company also belongs to the internal structure (Sveiby, 2001).

Lev (2001) states that intellectual assets consist of:

1) Innovation (discovery or knowledge);

2) Human resources; and

3) Organizational practices (capital) (Choong, 2008).

Marr and Chatzkel (2004) find that the researchers on intangibles often classify them into:

1) Human capital (employees' skills, talent and knowledge);

2) Information capital (information systems, databases and computer systems); and

3) Organization capital (culture, leadership, employee alignment, teamwork).

They conclude that in general, intangible assets are a collection of knowledge, intellectual and revenue generating resources (Choong, 2008).

As we proceed it will be obvious that none of the categorizations are apart from each other, though the notions are different the meaning lying behind them are very similar. Now that the categories of the umbrella sheltering intellectual capital has been specified, it's appropriate to move on to explore intellectual capital specifically.

The Organisation for Economic Co-operation and Development (OECD, 1999) describes intellectual capital as "the economic value of two categories of intangible assets of a company: organisational (structural) capital; and human capital (Guthrie and Petty, 2000). Though intellectual capital is generally classified into three dimensions there are also studies that classify it into two or further more into four dimensions. (Edvinsson and Malone, 1997; Stewart, 1997).

Sveiby (1997) is the first from the non-accounting perspective to propose the classification of intellectual capital, and he concludes that intangibles can be categorized into three sub-categories:

1) Employee (individual) competence;

2) Internal structure; and

3) External structure (Sveiby, 1997).

Edvinsson and Malone (1997), Bontis (1998), and Sullivan (1998) have adopted the similar three group categorizations of Sveiby(1997), but they termed these sub- categories as:

(1) Human capital;

(2) Organizational capital; and

(3) Customer capital (Edvinsson and Malone, 1997; Bontis, 1998; Sullivan, 1998). 
The Measuring Intangibles to Understand and Improve Innovation Management - MERITUM (2002) for the measurement of intangibles within the firm, the outcome of the MERITUM Project, have in many ways adopted the IC methodology of Sveiby (1997) as well; the classification includes three categories of intellectual capital:

1) Human resources;

2) Structural resources; and

3) Relational resources (Guthrie and Petty, 2000).

Stewart (1998) accepted Sveiby's categorization of the three sub-categories but instead of organizational capital he used the term structural capital (Stewart, 1998). Mouritsen et al. (2002), and Pablos (2003) separately used the same three-category classifications of intellectual capital as Sveiby and the above authors presented solidarity on, though, Pablos named the sub-category of "customer capital" as "relational capital" (Choong, 2008). Petty and Guthrie (2000) accepted the categorization of the OECD, accepting only two out of the three categories of Sveiby and these are human and organizational capitals (Guthrie and Petty, 2000). Roos et al. (1997) similarly classifies intellectual capital into structural and human capital which represents "thinking" and "non thinking" assets. This distinction acknowledges different management methods for human and structural capital (Tan, Plowman and Hancock,2008). Brookings (1996) on the other hand identified four components of intellectual capital:

1) Market,

2) Human-centerd,

3) Intellectual property; and

4) Infrastructure assets.

Tan, Plowman and Hancock (2008) argue that the difference between these classification systems is that they assume different levels of aggregation of the elements of intellectual capital (Tan et al., 2008).

Following the identification and classification of intellectual capital assets, during 2002 and 2003 a group of academics and experts developed a series of workshops at the Spanish Knowledge Society Research Center in Madrid. In those workshops, based on previous literature as well as on professional experience, a model of intellectual capital - called Intellectus (CIC, 2003) - was developed. It includes five components:

1) Human capital: indicates the tacit or explicit knowledge and the ability to create that knowledge possessed by the employees,

2) Technological capital: specifies the development of the activities and functions of the technical system of the organization directly linked with the combinatorial application of the knowledge,

3) Organizational capital: refers to the combination of explicit and implicit, formal and informal knowledge which in an effective and efficient way structures and develops the organizational activity of the firm,

4) Business capital: states the value to the organization of the relationships which it maintains with the main agents connected with its basic business processes - customers, suppliers, allies, etc; and 
5) Social capital: as the value to the organization of the relationships which it maintains with other social agents and its surroundings (Martin-de-Castro et al., 2006).

American Financial Accounting Standards Board (FASB), classifies intellectual capital to more specific seven categories; technology, customer, market, workforce, contract, organization, and statutory-based assets (Kaufmann and Schneider, 2004). "Intangible Assets in Accounting" of the Schmalenbach Society for Business identifies innovation capital, human capital, customer capital, supplier capital, investor capital, process capital, and location capital (Kaufmann and Schneider, 2004).

Although Marr et al. (2003) reviewed the literature on the measurement of intellectual assets, and identified that intellectual can be categorized into three main categories:

1) Strategy;

2) Influencing behavior; and

3) External validation. (Choong, 2008)

Marr and Adams (2004), according to the classifications of Sveiby (1997) Edvinsson and Malone (1997); Bontis, (1998); Sullivan (1998) and MERITUM (2002) find that there has been a general convergence towards a three-grouped framework consisting of:

1) Human capital;

2) Organizational (or structural) capital; and

3) Relational capital (Marr and Adams, 2004).

Rastogi (2003) concludes that a categorization of IC is hardly possible. However, he states that IC is the result of interaction between a firm's knowledge management, its social capital and human capital (Kaufmann and Schneider, 2004). Bukh et al. (2001) compare various taxonomies of IC and conclude that they all have three things in common:

1) The connection to employees;

2) The connection to processes and structures, and;

3) The services and value added activities connected to customers (Chong, 2008).

In this study the categorization of intellectual capital into three sub-categories is considered. Those sub categories are;

1) Human capital;

2) Organizational capital;

3) Relational capital.

Hence the description of these three categories will be presented. 


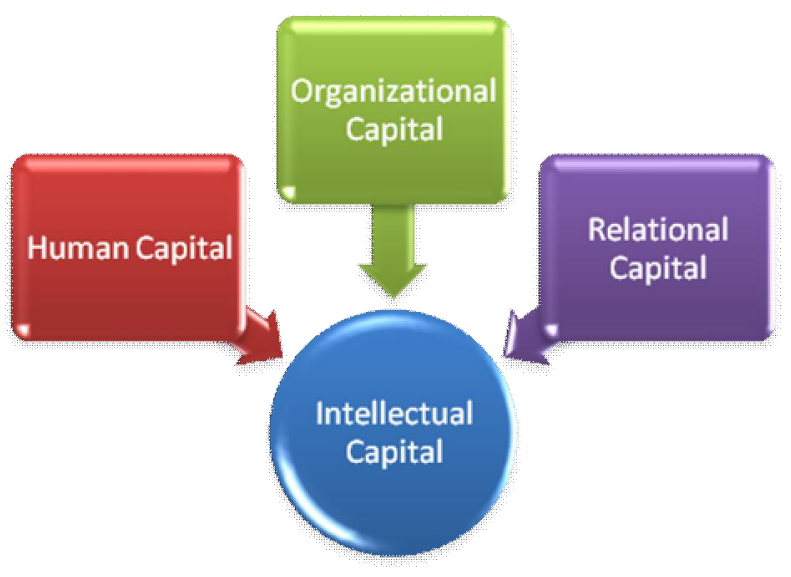

Figure 1. The categorization of intellectual capital.

Human Capital; is the knowledge, experience, capabilities and skills that are related with the employees and which are used through them within the organization (Subramaniam and Youndt, 2005: 451; Hsu and Fang, 2008: 2; Cuganesan, 2005: 358). The two determinants of the human capital are; the capabilities of the employees in the scope of both the intangible and tangible assets' production, the second determinant is the commitment of the employees to the organization (Y.-S. Chen, 2006: 1325). The reason why the employees' commitment (ie. loyalty) is important, is because, though some of the authors consider that human capital is part of intellectual capital, technically and legally, they are not properties that can be owned by the organization unlike other forms of intelectual capital. Hence, it is their decision to stay and generate value for the firm or to leave and generate value for another firm (Edvinsson and Malone, 1997; Stewart, 1998; Y.-S. Chen,2006). From a more broad perspective human capital is concerned with the skills, knowledge, innovativeness, capabilities, know-how, education and overall competence of the employees (Edvinsson and Malone, 1997; Sullivan, 1999; Seetharaman et al., 2004). Tovstiga and Tulugurova (2007) claims that human capital is constituted of three main attributes which are; competence (knowledge, skill sets, and experiential knowledge), attitude (level of motivation, behavioral patterns) and intellectual agility (innovation, creativity, flexibility, adaptability) of the enterprise's employees (Tovstiga and Tulugurova, 2007: 399). Human capital represents the stock of knowledge within an organization rather than in the minds of individual employees since these employees work for that firm and help generating, knowledge and ideas for that firm (Seethraman et al., 2004). Human capital interacts with both organizational and relational capital and represents the goods and services employees produce that bring revenues when there is an investment of their knowledge, skills, and other abilities (Isaac, Herremans and Klein, 2009). Sveiby (2001) defines human capital as the people's capacity to act in various situations and he claims that it includes skills, education, experience, values and motivation (Sveiby, 2001). Kong and Prior (2008) present the ideas of Bontis (2002) as; human capital is important to organizations as a source of innovation and strategic renewal. Thus, a higher level of human capital is often associated with greater productivity and higher incomes or compensation for employees (Kong and Prior, 2008). The value of all the collective human capital of the firm is hard to estimate but the million dollar insurance policies purchased on a key employee of the firm and high compensation packages (Seetharaman et al., 2004).

Organizational capital dimension; is identified with technologies and supporting systems that help employees to do their jobs and ultimately create revenues for the organization that result in corporate wealth. Organizational capital includes databases, technical and communication systems, policies, 
and other support mechanisms (Edvinsson and Malone, 1997; Kaufmann and Schneider, 2004; Ordonez de Pablos, 2003; Isaac, Herremans and Klein, 2009). Subramaniam and Youndt (2005) consider organizational capital as the institutionalized knowledge and codified experience residing within and utilized through databases, patents, manuals, structures, systems, and processes similar to other studies in the literature. It consists of three main aspects; relationships, relational networks including also the external players (involving strategic networks, alliances, relationships with customers and other key stakeholders, regulatory institutions), organizational routines, attributes, explicit codified knowledge (databases, routines, infrastructure, processes and culture), and renewal and development (research and development, investments in organizational learning) (Tovstiga and Tulugurova, 2007: 699). It is regarded as the most complex category of the intellectual capital and it has undergone several changes, and Choong (2008) claims that recently, some researchers have suggested it to include culture, innovation and process (Choong, 2008). The pool of knowledge that remains in an organization after individuals within the organization have left, represents the fundamental core of organizational capital (Kong and Prior, 2008), because organizational capital mentioned also as structural capital is the attribute integrating all the knowledge, skills, experiences, competences to the organization and help it to own all of those aspects, as Subramaniam and Youndt (2005) mention Daft and Weick's observation as, "Individuals come and go, but organizations preserve knowledge over time" (Subramaniam and Youndt, 2005: 351). Organizational capital is the supportive infrastructure for human and relational capital since in the absence of it both of the other capitals are not embedded in the organization. It includes all of the non-human storehouses of knowledge in organizations such as databases, process manuals, strategies, routines, organizational culture, publications and copyrights which creates value for organizations, thus adding to the organizations' material value (Ordonez de Pablos, 2004; Kong and Prior, 2008).

Relational capital can be explained as the flow of knowledge within and to the outside of the organization through the relational network constituted in and around the organization. Subramaniam and Youndt (2005) define relational capital as is the knowledge embedded within, available through, and utilized by interactions among individuals and their networks of interrelationships and term it as social capital (Subramaniam and Youndt, 2005: 451). Relational capital can be referred to in different names through the literature. Johansson et al. (2001), Sanchez et al. (2000), Stewart (1998), Edvinsson (1997) consider it as customer capital; Subramaniam and Youndt (2005), refer to relational capital as social capital, and Ordonez de Pablos (2003) identifies it as stakeholders. In the basis even there are different names of it, relational capital represents a dimension of intellectual capital that is comprised of connections with others within or outside the organization that lead to organizational value generation (Isaac, Herremans and Klein, 2009). It includes customer relationships, license agreements, brand value, trademarks, cooperation, relationship with customers and suppliers, firm reputation, organizational awareness, distribution channels and customer loyalty (Cuganesan, 2005: 358; Seetharaman et al., 2004: 524; Kong and Prior, 2008: 120). Wu et al. (2008) mentioned the three dimensions of organizational capital termed as social capital, proposed by Nahapiet and Ghoshal (1998). The first dimension is the structural dimension, comprising social interactions or network ties, the overall pattern of connections among all actors. The second dimension of social capital according to them is the relational dimension, which refers to assets that are rooted in relationships, such as trust and trustworthiness. The cognitive dimension is the third dimension of social capital, which refers to those resources providing shared representations, interpretations, and systems of meaning among parties (Wu et al., 2008: 266). Relational capital works more like organizational capital then human capital. Since social capital stems from norms for collaboration, interaction, and the sharing of ideas, it tends to be largely preserved within organizations without any dependence on 
changes in specific individual actors (Subramaniam and Youndt, 2005: 452). Relational capital is important to an organization because it acts as a multiplying element that creates value for the organization by connecting all IC components with other external stakeholders (Ordonez de Pablos, 2004).

Despite of all the discussions, Kaufmann and Schneider (2004) think that, in the end, all these categorizations stay at a very abstract level and that they do not offer direct guidance on the management of intangibles (Kaufmann and Schneider, 2004).

\section{Measurement and Reporting of Intellectual Capital}

Lord Kelvin stated that; "When you can measure what you are speaking about and express it in numbers, you know something about it; but when you cannot measure, when you cannot express it in numbers, your knowledge is unsatisfactory." The statement stressed in the works of Tan et al. (2008) and that of Leibowitz et al. (2000) stresses the importance of measuring concepts. The complexity of the intellectual capital's classification put limitations to the measurement and reporting of the intangible assets. The restrictions of traditional accounting practices such as existing financial reporting models lead to the evolution of new measurement and reporting models having the aim of synthesizing the financial and non-financial value-generating factors of the enterprise into one external report (Guthrie and Petty, 2000). The lack of a generally accepted methodology for valuing intangible assets has led to numerous efforts (Tan, Plowman and Hancock, 2008; Leibowitz and Ching, 2000).

Sveiby (2002) suggested four categories for the measurement approaches of intangibles. Thus these categories are an extension of the classifications suggested by Luthy (1998) and Williams (2000), argured by the work of Tan et al. (2008). These categories are:

1) Direct intellectual capital (DIC) methods or Dollar valuation Methods of Intellectual Capital: This method estimates the dollar value of intangible assets by identifying its various components ( Sveiby, 2002; Tan, Plowman and Hancock, 2008).

2) Market capitalization methods (MCM): MCM calculates the difference between a company's market capitalization and the book value of its shareholders' equity as the value of its intellectual capital. It's more of an accounting model (Sveiby, 2002).

3) Return-on-assets (ROA) methods: ROA method is the average pre-tax earnings of a company for a period of time divided by the average tangible assets of the company. The result is a company ROA that is then compared with its industry average. The difference is multiplied by the company's average tangible assets to calculate an average annual earnings from the intangibles. Dividing the above average earnings by the company's average cost of capital or an interest rate, one can derive an estimate of the value of its intangible assets or IC (Sveiby, 2002).

4) Scorecard methods (SCM) or Non- Dollar Valuation of Intellectual Capital: The various components of intangible assets or IC are identified and indicators and indices are generated and reported in scorecards or as graphs. SCM methods are similar to DIC methods, except that no estimate is made of the dollar value of the intangible assets (Sveiby, 2002; Tan, Plowman and Hancock, 2008).

In this study, non-dollar valuation of intellectual capital will be explained since it is the most accepted and studied measurement classification. 


\section{Non-Dollar Valuation of Intellectual Capital}

Balanced Scorecard model proposed by Kaplan and Norton (1992) is a pioneer in the measurement of intellectual capital without converting it to financial properties or dollar value. It is not a model specifically created for measuring the intellectual capital of an organization; rather, it tries to be a corporate management system and measure the results obtained at the heart of the organization, integrating for the first time the concept of intangible assets (Canizares, Munoz and Guzman, 2007: 411). It represents an important advance from the previous models of management as it considers that, being based exclusively on indicators of a financial kind, its base is absolutely obsolete. It measures the organizational performance across four dependent perspectives. The first is financial, which includes the cash-flows, product/service profitability, profitability of capitals, representing the final objective of the managerial result. The second is customer perspective that has driver indicators as the quality of the relationship with the customer, and the reputation of the company among its competitors and the output indicators as the results from the financial perspective (market quota, customer loyalty etc.) to determine the values related to the customers that increase the competitiveness of the organization. The third is internal business processes which propose an analysis of the internal processes (innovation, operations, post-sale services) in a way that makes them essential in the value chain, the aim is the increase of financial yield and customer satisfaction. Finally the last perspective is learning and growth define a group of values that enable improvement and continuous learning within the company and they are; capacity and competition of employees, systems of information, culture-climate-motivation for learning and action (Tan, Plowman and Hancock, 2008: 592; Canizares, Munoz and Guzman, 2007: 412). The BSC represents a set of cause-and-effect relationships amongst output measures and performance drivers. It provides for the control of intangibles while simultaneously monitoring financial results. The BSC provides the analysis of the organization from four important perspectives for the management which are (Tan, Plowman and Hancock, 2008: 592):

1) How do customers recognize the company?

2) What must the company succeed at?

3) Can the company continue to improve and create value?

4) How does the company view the shareholders?

Balanced Score Card method, sees that there are three groups of strategic individuals with different aims. These are the customers, who demand quality in the products and services offered, the investors, who want the value of the company to increase and the personnel of the company, who look for attractive pay packages and job security (Tan, Plowman and Hancock, 2008: 592). 


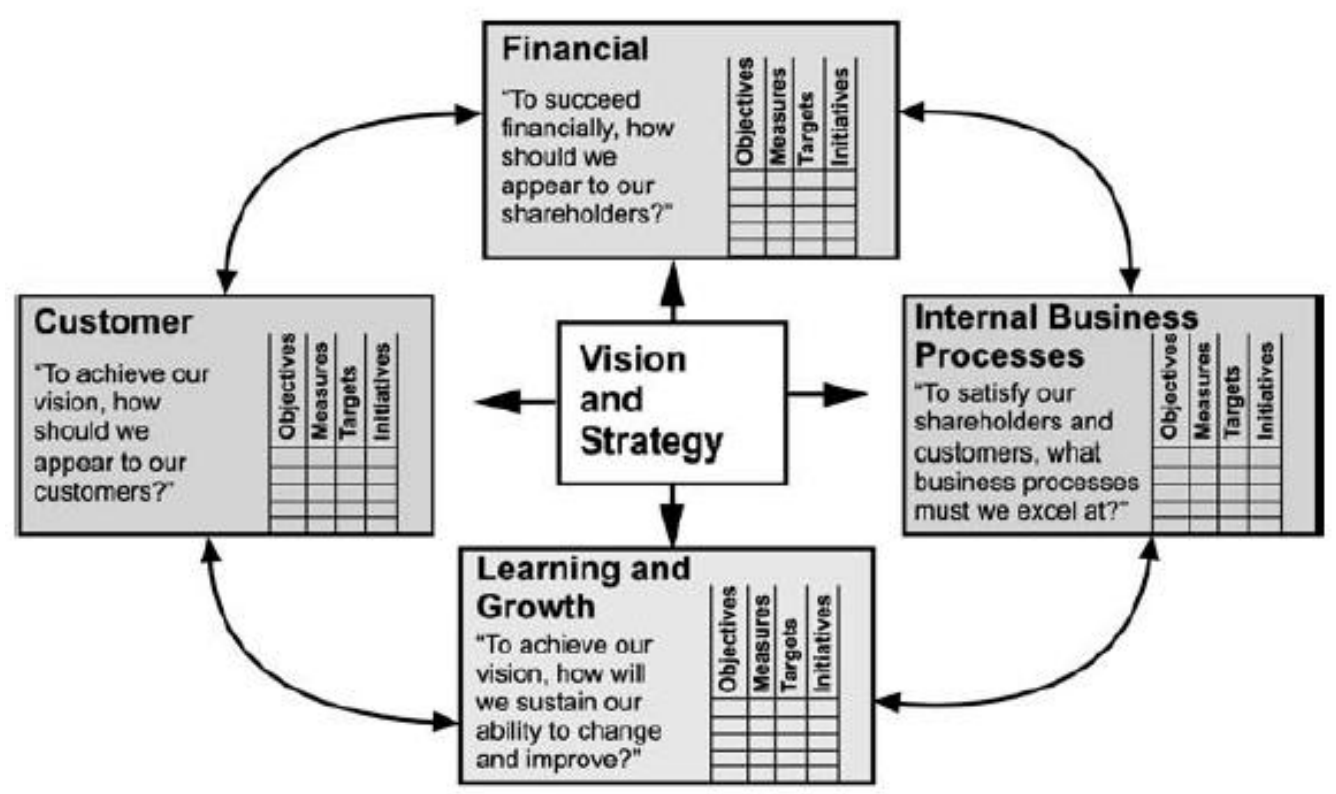

Figure 2. The Balanced Score Card Model of Kaplan and Norton

\section{Source: Canizares, Munoz and Guzman, 2007}

Another approach to measuring and reporting intellectual capital is Karl Erik Sveiby's "Intangible Assets Monitor" used by the Swedish company Celmi and it includes indicators referring to the growth, renewal, efficiency, stability, and risk relating to each of the three categories of intangibles (employee competence, internal structure, and external structure) (Sveiby, 1997; Kaufmann and Schneider, 2004). The intangible assets show the difference between the countable value and the market value of an organization. The measurement of these assets is a two-way process:

(1) toward the exterior, to inform the external agents with links to the company (clients, shareholders, suppliers);

(2) toward the interior, to inform the directors about the evolution of the company(Canizares, Munoz and Guzman, 2007).

Sveiby (1997) differentiates the intangible assets into three categories. Competence indicators which include competition between professionals in the organization, internal structure indicator, representing the structured knowledge of the organization like patents, models, informative systems, culture, and the group of people whose main activity is the maintenance of this structure and external structure indicators which are all the relationships with external agents such as customers, suppliers, the brand, and the image of the company. All of these intangible assets fall under the three types of categories offered by Sveiby; indicators of growth and innovation, indicators of efficiency and indicators of stability (Canizares, Munoz and Guzman, 2007; Kaufmann and Schneider, 2004; Sveiby, 1997). 


\begin{tabular}{|c|c|c|c|}
\hline & Competence & Internal structure & External structure \\
\hline $\begin{array}{l}\text { Growth/renewal } \\
\text { indicators }\end{array}$ & $\begin{array}{l}\text { Number of years in the } \\
\text { profession } \\
\text { Level of education } \\
\text { Training and education } \\
\text { costs } \\
\text { Marking } \\
\text { Competence turnover } \\
\text { Competence-enhancing } \\
\text { - customers }\end{array}$ & $\begin{array}{l}\text { Investment in new methods } \\
\text { and systems } \\
\text { Investment in informational } \\
\text { systems } \\
\text { Customer contribution to the } \\
\text { inner structure } \\
\text { Providing new services and/or } \\
\text { products } \\
\text { New processes installed }\end{array}$ & $\begin{array}{l}\text { Profitability per } \\
\text { client/customer } \\
\text { Organic growth } \\
\text { Sales to new } \\
\text { customers }\end{array}$ \\
\hline $\begin{array}{l}\text { Efficiency } \\
\text { indicators }\end{array}$ & $\begin{array}{l}\text { Professionals' } \\
\text { rate/proportion } \\
\text { Added value per } \\
\text { professional } \\
\text { Added value per } \\
\text { employee } \\
\text { Profit per professional } \\
\text { Profit per employee }\end{array}$ & $\begin{array}{l}\text { Rate of supporting personal } \\
\text { Sales per supportive person }\end{array}$ & $\begin{array}{l}\text { Sucoess/failure index } \\
\text { Profit per client } \\
\text { Sales per client }\end{array}$ \\
\hline $\begin{array}{l}\text { Stability } \\
\text { indicators }\end{array}$ & $\begin{array}{l}\text { Professionals turnover } \\
\text { Relative pay } \\
\text { Seniority }\end{array}$ & $\begin{array}{l}\text { Age of the organization } \\
\text { Support staff turnover } \\
\text { Rookie ratio } \\
\text { Seniority }\end{array}$ & $\begin{array}{l}\text { Proportion of great } \\
\text { customers } \\
\text { Customer satisfaction } \\
\text { index } \\
\text { Customers' loyalty } \\
\text { ratio } \\
\text { Antiquity structure } \\
\text { Repetition frequency }\end{array}$ \\
\hline
\end{tabular}

\section{Source: Sveiby (1997)}

Figure 3. The intangible assets monitor of Sveiby.

\section{Source: Canizares, Munoz and Guzman, 2007}

Another important measure is the Skandia Navigator model which is the first dynamic intellectual capital model. Its main developer was Leif Edvinsson. It appeared for the first time in 1992 in the memory of the company Skandia (Canizares, Munoz and Guzman, 2007). It's based on the difference between the value of the companies' assets and those of the market. This implies that a series of intangible properties exist, which are underestimated by the market as future bank flows (Canizares, Munoz and Guzman, 2007). This reporting technique utilises 112 metrics to measure five areas of focus (Edvinsson and Malone, 1997: 68). The five areas are; financial, customer, human, process and renewal and development. The financial perspective focuses mainly on the company's balance sheet that deals with the past activities of the firm. Customer, human and the process focus constitute the intellectual capital of a firm and represent the present stage of the firm. It is particularly impressive in recognizing the role of customer capital in creating value, and how the nature of customer relationships has changed (Tan, Plowman, Hancock, 2008; Canizares, Munoz and Guzman, 2007). Renewal and development perspective, as their contribution to organizational value has not been previously attempted and is the foundation that underpins the company's future (Tan, Plowman, Hancock, 2008; Canizares, Munoz and Guzman, 2007). The 112 indices are computed using direct counts, dollar amounts, and percentages or survey results as appropriate. Some examples of these indices are: Income per employee, value added per customer and invoicing per employee (Tan, Plowman, Hancock, 2008). Skandia's efforts on the measurement of a company's intangible assets has motivated others to search for "what creates value for organizations" (Tan, Plowman and Hancock, 2008). 


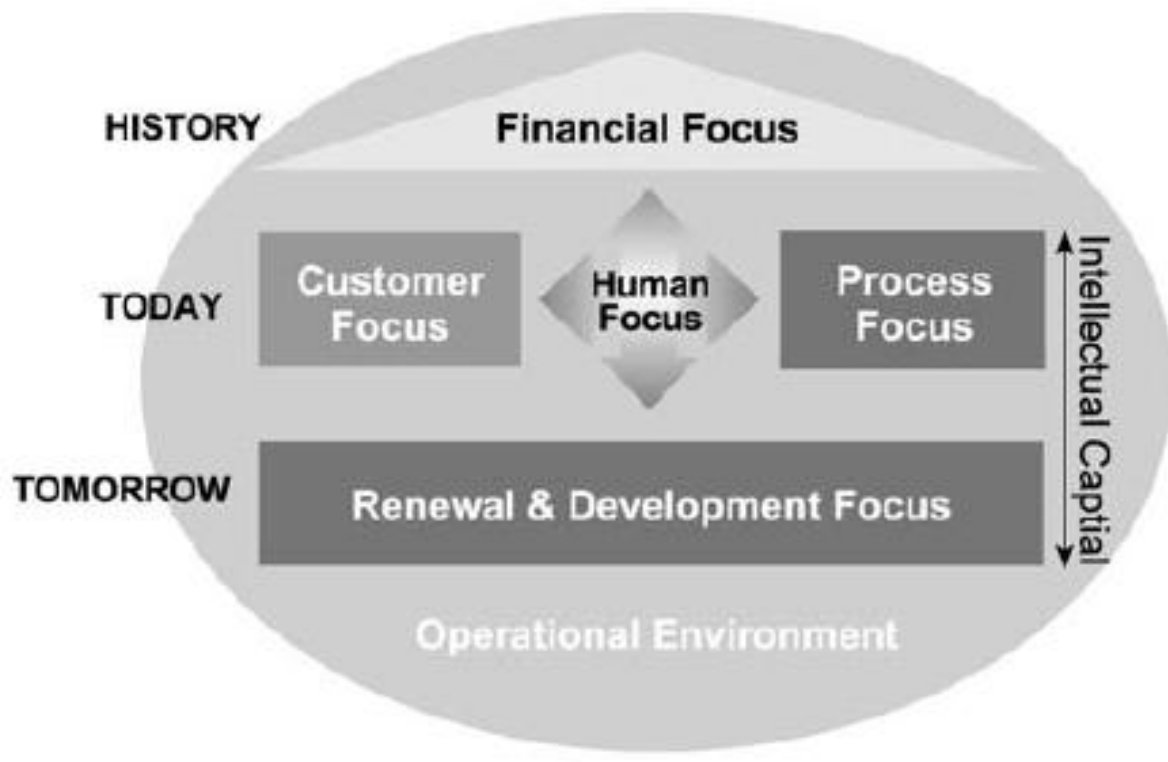

Figure 4. The Skandia Navigator.

\section{Source: Canizares, Munoz and Guzman, 2007}

Kaufmann and Schneider (2004) state that researchers have developed various models to measure and manage intangibles and these models were constructed for different purposes; some for external reporting and some to manage intangible resources within a firm. The authors conclude that model constructors were based on four categories of thought (Choong, 2008). The first category believes that management has a primary responsibility to transform human capital into structural capital (Edvinsson, 1997). They try to provide supplementary information to the annual financial report, and focus on agents within the firm. The second category is based on Sveiby's (1997) model known as the Intangible Asset Monitor, which includes information about growth, renewal, efficiency, stability, and risk relating to each category of intangibles (employee competence, internal structure and external structure). The third category is the model advocated by Stewart (1997). Stewart created an IC navigator in the form of a radar chart to visualize and measure the intangibles in a company. Here, each of the three types of intangibles (human capital, customer capital, and structural capital) is one axis (Stewart, 1998).

This category focuses in measuring each category of intangibles (human, customer, and structural capitals) and enable the intangibles reported to be compared with other firms. The fourth category of thought relates to the balanced scorecard (BSC) model developed by Kaplan and Norton (1996). In the latter model while the four perspectives (financials, customers, internal processes, and learning and growth) are not directly related to intangibles, they provide strategic company performance measurement in a holistic way that goes beyond the financial perspective (Choong, 2008: 625).

To answer the question why organizations are seeking to measure intellectual capital, Marr et al. (2003) identified five main reasons through the literature. The reasons are:

1) to help organizations formulate their strategy;

2) to assess strategy execution;

3) to assist in diversification and expansion decisions; 
4) to use these as a basis for compensation; and finally

5) to communicate measures to external stakeholders. (Marr, Gray, Neely, 2003)

Despite all the above models and frameworks represent important advances within the intellectual capital discipline; they silence the problematic nature of utilizing IC to create value. IC interrelationships and their consequences for value creation are unstable and precarious, being contingent upon the manner of their deployment and use within organizational processes (Cuganesan, 2005).

\section{Competitive Advantage in Relation to Intellectual Capital}

Sustained competitive advantage can be obtained when a firm develops a distinctive core competency (Hoffman et al., 2006: 140). What the literature appears to be suggesting is that competitive advantage increasingly is achieved by those firms that succeed in mobilizing their intangible assets in the form of knowledge, technological skills, experience, and strategic capabilities toward creating new processes and product or service offerings (Tovstiga and Tulugurova, 2007: 697). Hence the successful mobilization of these intangible assets may be identified as a distinctive core competency for the organization. The most common theory that examines competitive advantage of the firms, is resource based theory. We know from Schumpeter that resources can be important sources of innovation through new or different combinations of new or already existing resources (Schumpeter, 1934) and through their superior abilities (Hoffman et al., 2006: 140). While this is the conceptual basis of a framework that is developed to connect intellectual capital and the organization's environment (socio-political, economic and technological), the resource based theory of the firm, even more specifically the knowledge based theory where the firm's strategic knowledge is seen as the fundamental resource, identifies knowledge as the key competitive resource of the firm (Tovstiga and Tulugurova, 2007: 697). Tovstiga and Tulugurova (2007) view intellectual capital in its various forms as the primary resource available to these entrepreneurial endeavors.

What is meant by competitive advantage? Competitive advantage is mainly used to differentiate company performance in the profit-making sector. Competitive advantage is a concept that means much more than the financial performance and shareholder value; these are both a measurement at a moment in time, usually short-term. In today's globally competitive environment which requires, speed, dynamic capabilities, fast responsiveness and flexibility the objective of the organizations shifted from profit maximization to value maximization (Freeman, 2001). Hence the value of the firm that is generated through the intangible assets and more specifically through the intellectual capital carries more importance than financial profit. Competitive advantage is built slowly over time from a number of different aspects: one of the most important is organizational image and integrity (Freeman,2001). An independent consultant Olivia Freeman (2001) gave rise to the issue, how to gain competitive advantage for organizations by presenting the ideas of Professor Michael E. Porter from Harvard Business School who has been the guru of competitive strategy since 1980, when he published his classic book on the subject. Five years later, he took this a stage further and wrote a book called Competitive Advantage, which explains 'how a firm can actually create and sustain a competitive advantage in its industry'. Sustain is a key word. The professor claims that 'There are two basic types of competitive advantage: cost leadership and differentiation'. Among these two types of competitive advantage the factors that may lead to reach it are; sustained revenue, innovation and new product development/first to market, brand and reputation, advertising, media coverage, customer needs, customer service/satisfaction, employee relations, acquisitions and mergers, regulatory issues, political correctness, IT services that affect customer service (Freeman, 2001: 39). Mentioned by the Professor Porter, the differentiation is an essential aspect in the owning of com- 
petitive advantage. But to differentiate, you need to know what you are being different from and this would lead one to believe that the ability to monitor competitor activity and to provide accurate upto-date knowledge would be top level strategic skills in any organization (Freeman, 2001: 39). The study of Hoffman et al. (2006) refer to Prahalad and Hammel's (1990) observation about the core competency becoming a distinctive core competency -meaning that the firm differentiates from its competitors, not only when that company does that something very well (a core competency) but when the company does that something better than anyone else in the industry (a distinctive core competency) (Hoffman et al., 2006: 140). This competency then becomes a competitive resource, and if barriers exist that limit other firms' access to the resource, it becomes a long-term source of economic rents (Hoffman et al., 2006: 140).

There is an extensive literature that examines various enterprise-specific factors involved in creating a position of competitive advantage for the firm, and the complex interplay between the firm's internal organizational factors and environmental factors. Research evidence suggests that while environmental contexts can be very influential, they do not necessarily outweigh a number of key internal factors that can be directly influenced by the enterprise, while those in the firm's environment generally cannot (Hoffman et al., 2006: 140). Hoffman et al. (2006) argues the claims of Sanchez and McKinley (1998) who suggest that "whether or not environmental regulation inhibits or promotes product innovation seems to depend at least in part on certain internal features of an organization" (Hoffman et al., 2006: 140). From these arguments it's understood that to obtain a sustainable competitive advantage, organizations should place more importance on the internal factors rather than the external environmental conditions. The external conditions can only be controlled up to a point and even sometimes they cannot be controlled at all. On the other hand the internal resources, internal assets of the organizations are under the governance of organization itself. Accordingly the main vision of the organizations should be on the efforts to influence the internal organizational factors.

The impetus for organizations to build and sustain competitive advantage is well recognized in the strategic management literature (Kong and Prior, 2008). The utilization of knowledge has been a topic of interest in the strategic management literature, with some scholars suggesting that it is linked with the creation and maintenance of competitive advantage (Nonaka, 1994). One form of conceptualizing knowledge is through the study of intellectual capital (Roos et al., 1997; Bontis, 1998; Kong and Prior, 2008). As physical assets and financial capital are no longer the primary resources that facilitate competitive advantage in a knowledge based society, knowledge becomes the only means to competitive advantage (Kaplan and Norton, 2001; Kong and Prior, 2008). In examining the role of knowledge in supporting competitive advantage across the various disciplines, the possession of unique knowledge sets is seen as determining the extent to which competitive advantage can be sustained (Silvi and Cuganesan, 2006). The specificity of the knowledge possessed thus represents an important influence in the ability of the organization to achieve and maintain higher levels of performance in front of its peers, on the grounds of its greater potential to provide competitive differentiation and the difficulties associated with its imitation and replication elsewhere (Silvi and Cuganesan, 2006). The idea of competitive advantage is usually linked to extraordinary firm performance (Porter, 1985; Kong and Prior, 2008). The knowledge is not only the creation of people by themselves. Knowledge is a result of people's and groups' interaction which in the end provides the emerging of new organizational knowledge in the network. Since tacit knowledge is systematic when the knowledge is codified into routines, rules and activity procedures and the knowledge is codified into these routines, rules and procedures through structural capital, the tacit knowledge be- 
comes systematic with the use of structural capital within the intellectual capital. What makes a tacit knowledge systematic and opens it up to the usage, application and diffusion is structural capital.

Achieving competitive advantage in all markets would appear to be an attractive goal, yet the diversity of different stakeholders' needs would seem to make this a difficult proposition. The appropriate deployment of intellectual capital can provide access to multiple market opportunities in all the organizations (Kong and Prior, 2008). One important outcome of the explosion of computing power and connectivity in the last quarter of the 20th century is that it has as well redefined the role and economic importance of intangibles. Moreover, key intangible assets, such as know-how and high performance new business practices and new business models, now have the capability to be transferred rapidly around the world. It has also served to destabilize the old-world value-delivery model and create a wholesale disaggregation of the corporate value system. Value chains always had a limited life in competitive markets, but are now eroding much faster than in the past. Hence the critical importance of an effective "innovation machine" to keep one step ahead is understood. Continuous evolution and renewal of this capability is the main preoccupation of corporate strategy today (Eustace, 2003). The modern economy is characterized by mature markets for goods and services. As markets have become increasingly mature (commoditized), so firms have to compete harder for monopoly profits or comparative advantage (Eustace, 2003). All these factors force firms to deepen their search for new factors of differentiation and market leverage, not only in the "new economy" sectors but in the mature industries struggling to keep their business models evolving at least at the pace of the market (Eustace, 2003). Eustace states that, "A new market model is emerging - where sustainable value-creation is geared less to economies of scale than the exploitation of innovation, arbitrage and scope effects. Subtly, and incrementally over several decades, this has resulted in a fundamental shift in the corporate value system, away from physical and financial assets (now commoditized) towards the creative exploitation of a nexus of intangible assets, quasi-assets and competences - mainly in the form of distinctive capabilities deriving from knowledge intangibles - that have become essential ingredients of the economic production process" (Eustace, 2003).

\section{Conceptual Framework and Hypotheses}

The competency literature contains a number of indicators as to what can be considered a competency or core capability. The essential components of these definitions are that it results from combining resources, that it contributes to competitive advantage, that the competency can be used to access multiple market opportunities, and the competency is able to be preserved (Teece et al., 1997; Kong and Prior, 2008). The three components of intellectual capital; human capital, organizational capital and relational capital can also be viewed as resources. The resources in the resource based view literature are defined as "anything which can be thought of as a strength or weakness of a given firm" (Priem and Butler, 2001). Some more specific definitions consider resources as being specific assets, or combinations of assets (Schumpeter, 1934) that own the property of being valuable, inimitable, non-substitutable and rare (Priem and Butler, 2001; Srivastava, Fahey and Christensen, 2001). That is the reason why when a distinctive core competency is obtained, it leads the organization to the competitive advantage because the competitors cannot imitate, substitute or transfer that specific organization's distinctive core competency easily. Lopez et al. (2006), define resources as; "any production factor that is ready for the company, which is to say that it can be controlled in a stable manner, even if it does not entail clear property rights" (Lopez et al., 2006: 325). The most accepted descriptions of resources consider both tangible and intangible assets as resources (Penrose, 1959; Teece et al., 1997; Kong and Prior, 2008). Knowledge management is seen as the process of manag- 
ing the intellectual capital of an organization. Given, that in most cases, the economic and productive capacity of an organization "lies more in its intellectual and service capabilities than its hard assets" it is increasingly recognized that the performance of any organization, private- and public-sector, is substantially dependent upon the knowledge of its employees, the application of that knowledge to the structures of the organization, and its relationships (Silvi and Cuganesan 2006). Hence, intellectual capital, regarding its definition and categorization meets all of the conditions of being a resource which is; organization specific, inimitable, non-substitutable, rare and non-transferable. Intellectual capital provides the integration of the intangible assets that it includes within its components (human, organizational and relational capital) to the organization through the collaborative tasks it holds in its structure.

The creation and maintenance of human capital allows the organizations to develop new ideas and innovations through better-trained, more focused staff and higher employee morale (Kong and Prior, 2008). New ideas and new innovations mean new knowledge, new inputs to organizational memory and new sources of value generation. Kong and Prior (2008) position the words of Knight (1999) in their study saying: “....as investments are made in human capital, more competent and capable people develop better structural capital for an organization. Improved human capital and structural capital go on to create more productive external [relational] capital through the delivery of better products and services to high-value customers . . . a virtuous cycle begins its upward spiral into further organizational value and growth" (Kong and Prior, 2008). The specificity of the knowledge possessed thus represents an important influence in the ability of the organization to achieve and maintain higher levels of performance in front of its peers, on the grounds of its greater potential to provide competitive differentiation (Silvi and Cuganesan, 2006). Knowledge innovation is a key element in the creation of product value and economic growth in a knowledge-based economy (Hsu and Fang, 2008). In the discussion made by Hsu and Fang (2008), Baker (1992) reflects that high-quality employees are the most important factor for a firm in this economy. Managers train their employees to be knowledgeable workers, improve their overall quality, and increase organizational learning capability. Hsu and Fang get support from the ideas of Pfeffer (1994) who notes that the manner in which a firm retains and trains its best human resources is the most important competitive strategy within the knowledge economy context (Hsu and Fang, 2008). The more long-serving, experienced, and proven people are employed in an organizations, they provide the wisdom, and their wisdom is the key to future corporate success. In today's turbulent world it could be that the younger, open minded, and cavalier business brains are better equipped for information age companies. These people do not necessarily have conventional skills sets but they have the creative ability for the generation of new knowledge, new processes, new systems etc.

Hypothesis 1a: Human capital positively influences structural capital.

Hypothesis 1 b: Human capital positively influences relational capital.

Hypothesis 1 c: Human capital positively influences competitive advantage.

In examining the role of knowledge in supporting competitive advantage across the various disciplines, the possession of unique knowledge sets is seen as determining the extent to which competitive advantage can be sustained (Silvi and Cuganesan, 2006). The specificity of the knowledge possessed thus represents an important influence in the ability of the organization to achieve and maintain higher levels of performance in front of its peers, on the grounds of its greater potential to provide competitive differentiation and the difficulties associated with its imitation and replication elsewhere (Silvi and Cuganesan, 2006). The idea of competitive advantage is usually linked to extraordi- 
nary firm performance (Porter, 1985; Kong and Prior, 2008). The knowledge is not only the creation of people by themselves. Knowledge is a result of people's and groups' interaction which in the end provides the emerging of new organizational knowledge in the network. When the knowledge is codified into routines, rules and activity procedures the tacit knowledge becomes systematic with the use of structural capital within the intellectual capital. What makes a tacit knowledge systematic and opens it up to the usage, application and diffusion is structural capital (Kong and Prior, 2008). Therefore, following the cycle that; the knowledge possessed influences the ability to maintain higher levels of performance, performance is an indicator of competitive advantage in the strategic management literature and knowledge is embedded into the organization through structural capital. This discussion concludes that structural capital influences the achievement of competitive advantage. Similarly an information technology perspective emphasizes the development of infrastructure for a knowledge-based organization. IT applications allow firms to better capture, storage, retrieval and share documented knowledge (Silvi and Cuganesan, 2006). Specifically organizations are implementing decision support and expert systems, database management, online document systems repository, internet, intranet and extranet applications in order to enable managers to route, share and distribute information and codify knowledge (Silvi and Cuganesan, 2006). Moreover, Lopez et al. (2006) focus to three main components of organizational capital; culture, structure and organizational learning. The first component contributes to the generation of value internally and externally. From an internal perspective; firms that are successful at obtaining productivity through their people generally have an organizational culture that supports and values the contribution of the employee. From an external point of view, organizations that have strong customer cultural values stay close to their customers, providing in timely market information, joint product development activities, and intense product loyalties (Lopez et al., 2006: 329). About the structure of the organization; the main issue is that the formal structure of the organization and its external links play an important role in innovation management and in how the competences and capabilities evolve. It can be deduced that the value of the structure will be based on its fit to the environment conditions (Lopez et al., 2006: 329). So, Lopez et al. (2006) conclude that, the structure is a necessary capability for the organization, and although it is difficult to imitate and to transfer, its duration can be variable and is susceptible to substitution, so it can be a source of competitive parity (Lopez et al., 2006: 329). Finally, Lopez et al. (2006) mentions the organizational learning as a source of sustainable competitive advantage. It is the ability of the company to manage and to mobilize its resources in a competitive response, and it is a key for firm adaptability, and makes learning a combinative capability (Lopez et al., 2006: 332). Thus organizational learning is a valuable organizational capability, difficult to imitate, to replace, and to transfer. Besides it has a prolonged life expectancy and it does not show difficulties for rent appropriation (Lopez et al., 2006: 332). To conclude, Lopez et al. (2006), state that organizational learning and culture show the highest potential for sustaining competitive advantage, though structure take risks of imitation and substitution by competitors, and their value to the firm is limited to a competitive parity (Lopez et al., 2006: 332).

Hypothesis 2: Organizational capital positively influences competitive advantage.

Specifically; relational capital enables the links between diverse groups and organizations, while also providing a rationale for continued inter and intra organizational relationships with a variety of stakeholders (Kong and Prior, 2008). Huang and Chang (2008) refer to Uzzi’s (1996, 1997) statement that trust acts as the governance mechanism of embedded relationships. Trust is expressed as confidence in a partner not to exploit the vulnerability of the other party. Trust exists when one party has confidence in an exchange partner's reliability and integrity. Business networks with high embeddedness can develop trust and support a rich exchange of information among their members 
(Huang and Chang, 2008). Commitment concerns the future stability of a relationship and suggests a future orientation. Huang and Chang (2008) developed a framework; where "commitment" is defined as an implicit or explicit pledge of relational continuity between exchange partners and implies a willingness to make short-term sacrifices in the interest of longer-term benefits. Relationship commitment exists when an exchange partner believes that an ongoing relationship with another is so important as to warrant maximum efforts at maintaining it, according to Morgan and Hunt (1994) mentioned by Huang and Chang (2008). Huang and Chang (2008) presents also the ideas of Nielsen (1998) and Fujimoto (2003) suggesting that closeness between partners and embedded ties are positively associated with a commitment to the relationship encouraging each party and that an embedded tie encourages each party to make considerable commitments (Huang and Chang, 2008). The creation and maintenance of effective interactions, good relationships with the customers, suppliers, distributors, stakeholders, partners, investors and the government will increase the reputation, the credibility, customer satisfaction, government and financial support, brand awareness and customer/ supplier loyalty of the organization. This will push the firm one step forward within its competitors. The maintenance of effective interactions and good relationships can be obtained through the relational capital. Alliances, partnerships and other forms of inter-firm relationships have been prescribed as effective choices for gaining, leveraging, or developing new competencies and resources (Silvi and Cuganesan, 2006). As it is also mentioned before according to Tovstiga and Tulugurova (2007) the literature suggests that competitive advantage is increasingly obtained by the organizations that succeed to mobilize their intangible assets in the form of knowledge, technological skills, experience, and strategic capabilities toward creating new processes and product or service offerings (Tovstiga and Tulugurova, 2007: 697). Examining the definition of relational capital, it appears as; the flow of knowledge within and to the outside of the organization through the relational networks constituted in, and around the organization. Since competitive advantage is achieved by mobilization of intangible assets, and since the mobilization of intangible assets inside and outside of the organization is achieved through relational capital; relational capital has an important role in the achievement of competitive advantage. Hence the relational capital will be able to create competitive advantage for the firm through the establishment of a distinctive core competency in the form of relationships embedded into organization controlled networks (Subramaniam and Youndt, 2005).

Hypothesis 3a: Relational capital positively affects the creation and maintenance of effective interactions and good relationships.

Hypothesis 3 b: The creation and maintenance of effective interactions and good relationships positively affects competitive advantage.

Hypothesis 3 c: Relational capital positively affects competitive advantage.

Formulation of strategy in order to reach to the objectives determined by an organization will generate competitive advantage for the organization. The strategic management literature focuses on the concept of performance increase. The strategy formulation is the instrument in the achievement of high performance. The achievement of high performance provides the outcome of competitive advantage (Meyer et al., 2002). The strategy formulation can be thought as the modeling of a simulation for the analysis of inputs/datasets, limitations/constraints and outputs/results. The strategy constitutes a pathway in the achievement of the objectives. Marr et al. (2003) refer to the definition of Kenneth Andrews (1971) about the corporate strategy as "the pattern of decision making in a company that determines and reveals its objectives, purposes, or goals, produces the principal policies and plans for achieving those goals, it defines the range of business the company has to pursue, the 
kind of economic and human organization it is or intends to be, and the nature of the economic and non-economic contribution it intends to make to its shareholders, employees, customers, and communities." In addition to examining, the strategy identifies the competitive forces, opportunities, and threats of the industry, besides organizations have to identify their corporate competence and resources in order to evaluate opportunities. The question; "does the organization have the right competence to pursue certain opportunities?" has to shed light to the pathway of the organizations (Marr, Gray and Neely, 2003). Kenneth Andrews brings the strategic importance of competences to ahead when he states that "opportunism without competence is a path to fairyland" mentions, Marr et al. (2003). This is examining the intellectual capital possession of the organization itself and knowing how to utilize and integrate it into business strategy. An important objective of this phase is to identify the intellectual capital between business strategy and the capabilities of the existing intellectual capital structure (Tan, Plowman and Hancock, 2008). Rylander and Peppard (2003) propose a concept which links competitive strategy, identity and intelectual capital for knowledge intensive companies competeing in uncertain environments. The proposed concept supports the idea that the strategy and intellectual capital as a resource are linked and need to be mobilised to succeed the strategy. Many of the most critical resources in a knowledge-intensive firm are intellectual capital resources like structures, processes, systems, culture, brands, competencies and relationships with customers. The financial and physical resources support the intellectual capital resources and are an integral part of a firm's strategy (Tan Plowman and Hancock, 2008). Regarding all the above discussion, the tool in the determination of decision making pattern of a company, with the analysis of; strengths and weaknesses in facing opportunities and threats, is intellectual capital. Human capital determines the strengths and weaknesses (knowledge, skills, capabilities, experiences, performance, education, behavior, loyalty, commitment, satisfaction etc.) of the employees. Organizational capital provides for the codification of the knowledge, skills, capabilities, organizational culture, organizational learning capabilities all the intangible assets owned by the organization to the structure of the firm through technological systems, routines, patents, processes, software, hardware and organizational management. So that the competences creating value are hard to imitate, transfer or steal from the integrated structure of the organization. The relational capital explores internal and external opportunities and threats by the intra and inter-organizational relationship networks constituted. Hence the awareness of the threats and opportunities awaiting will lead the organization to take right steps regarding their strengths and weaknesses explored by intellectual capital's components in collaboration. Therefore, firms need to strategically identify and develop their intellectual capital in order to gain a competitive advantage and to increase their performance (Marr et al., 2006). The key to a resource-based approach to strategy formulation is to understand the relationships between intellectual capital, competitive advantage, and profitability (Marr, Gray and Neely, 2003).

Hypothesis 4 a: Intellectual capital positively affects the strategy formulation through the exploration of strengths, weaknesses, opportunities and threats.

Hypothesis 4 b: The strategy formulation positively affects the competitive advantage.

Hypothesis 4 c: Intellectual capital positively affects competitive advantage.

Given the increasing importance of innovation as a major competitive weapon for many organizations (Porter, 1990), after decades of research in a wide range of disciplines, including economics, marketing, and organization behavior, Huang and Chang (2008) identified Chandrashekaran et al.'s, (1999) argument, which have centered on a fundamental question: “what 
are the drivers of innovation" (Huang and Chang, 2008). The acceleration of R\&D efforts and the development of internal innovative capabilities are no longer sufficient to cope with the increasing cost, speed, and complexity of technological developments. In recent decades, there has been unprecedented growth in corporate partnering and an increasing reliance on various forms of external collaboration (Huang and Chang, 2008). A growing body of literature, focusing on different industrial sectors and both large and small firms, regards collaborative practices as a viable method of knowledge creation and transfer (Huang and Chang, 2008). Thus, innovation generation has increasingly become recognized as an outcome of the relationship between a firm and outside entities (Huang and Chang, 2008). Learning is a related issue because rapid and proactive learning leads to knowledge expansion, and this in turn is the engine for corporate renewal. Learning provides the ability to adapt, innovate and compete. Learning is vital to an organization's sustained competitiveness. In fact the value of learning has risen steadily as a result of the speed of change: as situations constantly shift and alter, managers are foolish if they believe they have all the answers (Freeman, 2001). What matters now is not how much people know, but how they react to what they do not know (Freeman, 2001). Recently, knowledge-sharing with suppliers has received increasing research attention (Huang and Chang, 2008). Manufacturers have discovered the managerial, technological, and financial benefits that may accrue as a result of close ties with suppliers. Scholars also generally agree that a substantial part of the innovation process occurs between buyers and sellers in the supply chain. Accordingly, a large body of strategy-level research on buyer-seller interaction and innovation outcomes has emerged. Huang and Chang (2008) argue that an embedded tie between a manufacturer and the primary supplier provides a foundation of trust, joint problemsolving and commitment mechanisms. These mechanisms enable joint action between partners to facilitate incremental innovation (Huang and Chang, 2008). Further, we know that through the combinations we can devise competitive positions or distinctive core competencies that yield us rents. These rents can be long lasting if the resource in question is rare, inimitable, and nonsubstitutable (Hoffmann et al., 2006: 140). If the position that resource provides is more difficult for other competitors to catch up then it means that the organization succeeded to add the quality of longevity to that resource. The capability of innovating is a possible way of creating such a resource. Innovation is not imitable, once imitated it turns out to be not new anymore, it is rare because not every organization can result its research with a radical or incremental innovation and it's nonsubstitutable because it is unique and obtained as a result of efforts that are hard to compensate (Hoffmann et al., 2006: 140). As a result of the above discussion the following hypothesis can be proposed;

Hypothesis 5 a: Relational capital positively influences innovation.

Hypothesis 5 b: Relational capital positively influences competitive advantage. Through the mediating role of innovation.

Hypothesis 5 c: Innovation positively influences competitive advantage. 


\section{The Proposed Model}

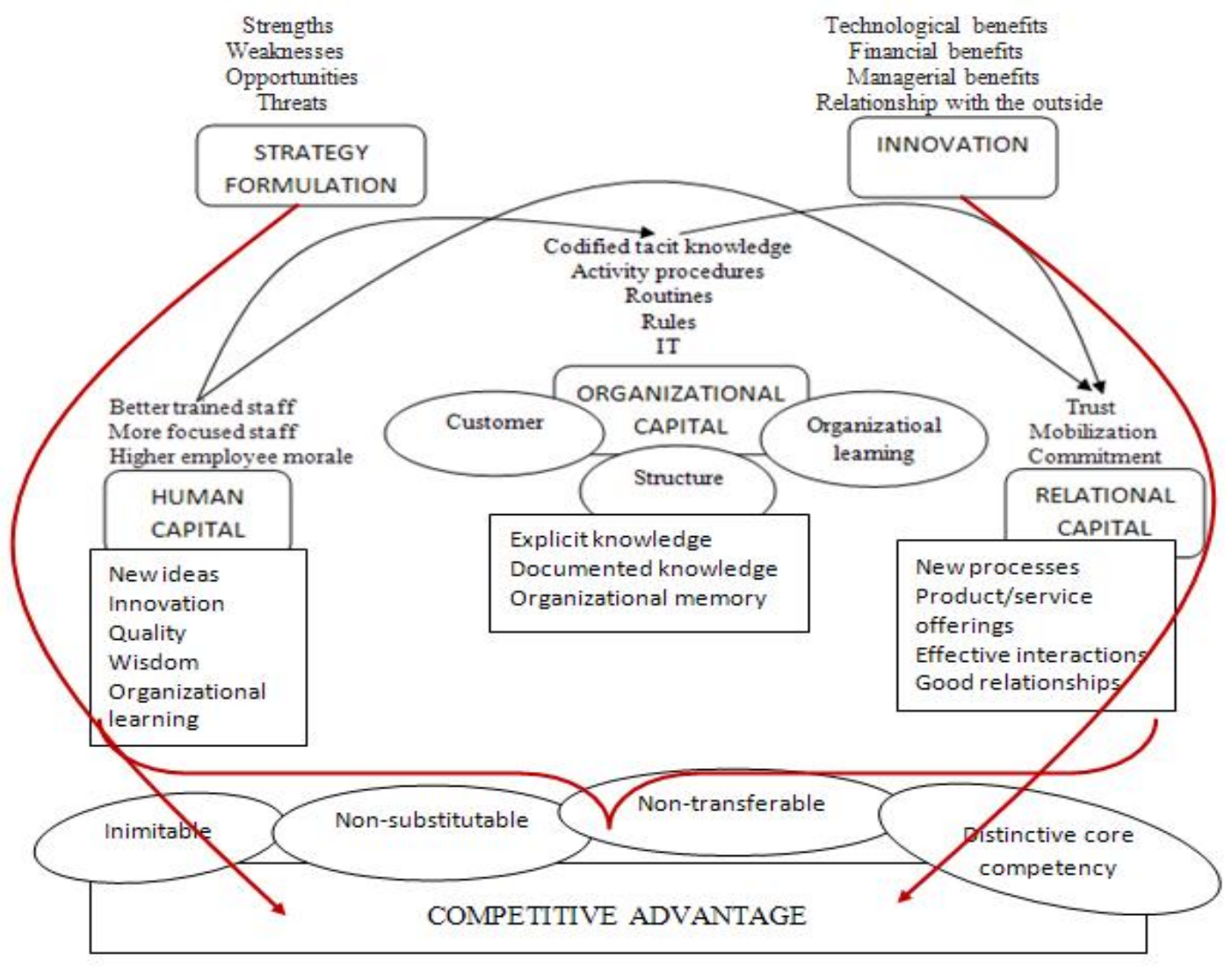

Figure 5. The proposed model, representing the relationship between competitive advantage and intellectual capital.

\section{METHODOLOGY}

This study aiming to obtain the conceptual framework underlining, the relationship between the intellectual capital and the competitive advantage, is based on an extensive literature review. The methodology consisted of developing a conceptual framework, where 5 hypotheses are presented regarding the relationship between intellectual capital and competitive advantage. The first hypothesis focused on the human capital's relationship with competitive advantage and according to the extensive literature review; the statement resulted as human capital positively influences competitive advantage. The second hypothesis is based on the positive influence of organizational capital on competitive advantage. The third hypothesis states that the relational capital positively influences competitive advantage. The fourth hypothesis is about the positive influence of intellectual capital on strategy formulation and the positive influence of strategy formulation on competitive advantage. Therefore, the intellectual capital positively influences the competitive advantage hypothesis is obtained. And the last hypothesis is that innovation positively influences competitive advantage through the relational capital. A possibility of future research is the testing of the hypotheses with the application of survey method to the industrialists of selected sample pool. The next study regarding the statistical support to the present study will consist of a two-stage research design. The first stage will be based on the determination of compatible measures of 
intellectual capital and competitive advantage, by the examination of previous studies. The second stage will be consisting of questionnaires, aiming to gather data about the intellectual capital and competitive advantage measures of the organizations. The questionnaires will be sent to the selected sample pool of product managers, project managers and $R \& D$ engineers via e-mail. Using a fivepoint Likert-type scale the obtained results will be used to measure different aspects of intellectual capital having influence on the creation of competitive advantage in strategic management context.

\section{CONCLUSION}

The main purpose of this study has been to explore the intellectual capital, rather than the traditional tangible assets -land, facility, work force, physical and financial capital- considered as capital, in depth as a crucial factor creating the competitive advantage for the organizations in turbulent markets, shifting towards dynamic nature and mainly from production based to the knowledge based economy. In addition to examining the intellectual capital, the relationship between firm intellectual capital and competitive advantage is focused on. This study develops a platform through which intellectual capital shapes the strategic management of the organizations for the aim of achieving the competitive advantage. Previous studies rarely examined the connection and relevancy of intellectual capital, and the competitive advantage. Noticing the transformation of firms' main goals from the profit maximization to value maximization, the intellectual capital that assures the creation and management of knowledge became the most important asset of the knowledge based economy, since the knowledge is the creator of value and effective management of knowledge is the fundamental instrument in maximizing value. This study contributes to the literature by proposing a theoretical model considering the relationship of intellectual capital with the generation of competitive advantage in knowledge intensive organizations.

Significant organizational change can be obtained through the role of intellectual capital constituting the basis for distinctive core competency. While in the past successful positioning with the effect of a unique technology or dominance in a market were considered sources of competitive advantage, but recently it is acknowledged that long-term winning strategies which can be acquired through the accumulation and successful utilization of organizations' intellectual capital are the sources of sustained competitive advantage. In the study of Tan et al. (2008) Marti's (2001) statement is reflected by a strategic perspective in which intellectual capital has the key role in the creation of knowledge that enhances firm value; "the only thing that gives an organization a competitive edge, the only thing that is sustainable, is what it knows, how it uses what it knows, and how fast it can know something new. The key role of knowledge as a source of competitive advantage is to produce intellectual capital in an efficient way" (Tan, Plowman and Hancock, 2008). Capabilities and competences that are difficult to replicate, in the means of uniqueness within the competitors are the outputs of the whole intellectual capital pattern of the organization. The five propositions in this study present "the role of intellectual capital in shedding light for the path extending to sustained competitive advantage". The arguments of the study focus on the positive influence of intellectual capital on the organizations' competitive advantage through the direct and indirect roles of five dependent variables; human capital, organizational capital, relational capital, strategy formulation and innovation. The enriched effectiveness of these five elements' integrated structure has a unique impact on the competitive advantage. The constituted frame has four main common characteristics; inimitable, non -substitutable, non-transferable and distinctive core competency which are the common properties of the variables in the model, when combined together constitute the unique empowerment by intellectual capital on the competitive advantage. 


\section{REFERENCES}

Anell, B.I. and Wilson, T.L. (2002), "Prescripts: creating competitive advantage in the knowledge economy”, Competitiveness Review, Vol. 12 No. 1, pp. 26-37.

Arenas, T. and Lavanderos, L. (2008), Intellectual Capital: Object or Process, Journal of Intellectual Capital, 9 (1), pp. 77-85.

Carneiro, A. (2000), "How does knowledge management influence innovation and competitiveness?", Journal of Knowledge Management, Vol. 4 No. 2, pp. 87-99.

Civi, E. (2000), "Knowledge management as a competitive asset", Marketing Intelligence \& Planning, Vol. 18 No. 4, pp. 166-74.

Chang, L. and Birkett, B. (2004), Managing intellectual capital in a professional service firm: Exploring the creativity-productivity paradox, Management Accounting Research, 15, pp. 7-31.

Chen, Y.-S., Lin, M.-J., Chang, C.-H. (2006), The Influence of Intellectual Capital on New Product Development Performance- The Manufacturing Companies of Taiwan as an Example, Total Quality Management, 17 (10), pp. 1323-1339.

Choong, Kwee, K. (2008), Intellectual capital: definitions, categorization and reporting models, Journal of Intellectual Capital, 9 (4), pp. 609-638.

Cuganesan, S. (2005), Intellectual Capital in Action and Value Creation, Journal of Intellectual Capital, 6 (3), pp. 357- 373.

Feland, J., M. (2005), Product Capital Model: Modeling the Value of Design to Corporate Performance, pp. 1-136.

Greeve, Henrich, R. (2009), Bigger and Safer: The Diffusion of Competitive Advantage, Strategic Management Journal, 30, pp. 1-23.

Hofman, J., Hoelscher, M. and Sorenson, R. (2006), Achieving Sustained Competitive Advantage: A Family Capital Theory, Family Business Review, 19 (2), pp. 135-145.

Isaac, R., Herremans, I. and Kleine, T. (2009), Intellectual Capital Management: Pathways to wealth Creation, 10 (1), pp. 81- 92.

Kaufmann, L. and Schneider, Y. (2004), Intangibles: A synthesis of current research, Journal of Intellectual Capital, 5 (3), pp. 366- 388.

Kong, E. (2008), The Development of Strategic Management in the Non-Profit Context: Intellectual Capital in Social Service Non- Profit Organizations, International Journal Management Reviews, 10 (3), pp. 281-299.

Marr, B., Gray, D. and Neely, A. (2003), Why do firms measure their intellectual capital? Journal of Intellectual Capital, 4(4), pp. 441-464.

Martin-de-Castro, G., Navas-Lopez, J.E., Lopez-Saez, P. and Alama-Salazar, E. (2006), "Organizational capital as competitive advantage of the firm", Journal of Intellectual Capital, Vol. 7 No. 3, pp. 324-37. 
McPhail, K. (2008), Where is the Ethical Knowledge in the Knowledge Economy? Power \& Potential in the Emergence of Ethical Knowledge as a Component of Intellectual capital, Critical Perspectives in Accounting, 1-39.

Montequin, Vincent R., Fernandez, Francisco O., Cabal, Valeriano A. and Gutierrez, Nieves R. (2006) An Integrated Framework for Intellectual Capital Measurement and Knowledge Management Implementation in Small and Medium-Sized Enterprises, Journal of Information Science, 32 (6), pp. 525-538.

Nonaka, I. (1995), The Knowledge Creating Company, Harvard Business Review on Knowledge Management, Harvard Business School Press, Boston, MA, 1998, pp. 21-45.

Petty, P. and Guthrie, J. (2000), "Intellectual capital literature review: measurement, reporting and management", Journal of Intellectual Capital, Vol. 1 No. 2, pp. 155-75.

Sanchez-Canizares, Sandra M., Miguel A. and Lopez-Guzman, T. (2007), Organizational culture and intellectual capital: a new model, Journal of Intellectual Capital, 8(3), pp. 409-430.

Schulze, A. and Hoegl, M. (2006), Knowledge Creation in New Product Development Projects, Journal of Management, 32 (2), pp. 210-236.

Seetharaman, A., Low, K. and Saravanan, A., S. (2004), Comparative Justification on Intellectual Capital, Journal of Intellectual Capital, 5 (4), pp. 522-539.

Subramaniam, M. and Youndt, M. (2005), The Influence of Intellectual Capital on the Types of Innovative Capabilities, Academy of Management Journal, 48 (3), pp. 450- 463.

Tan, Hong P., Plowman, D. and Hancock, P. (2008), The evolving research on intellectual capital, Journal of Intelectual Capital, 9(4), pp. 585-608.

Tovstiga, G. and Tulugurova, E. (2007), Intellectual Capital Practices and Performance in Russian Enterprises, Journal of Intelectual Capital, 8 ( 4), pp. 695- 707.

White, Larry N. (2007), Unseen Measures: The Need to Account for Intangibles, The Bottom Line, 20 (2), pp. 77-84.

Wu, Y.-W., Chang, M.-L. and Chen, C.-W. (2006), Promoting innovation through the accumulation of intellectual capital, social capital, and entrepreneurial orientation, R\&D Management, 38 (3), pp. 265-277.

Y.-H. Hsu, and W. Fang, (2008), Intellectual capital and new product development performance: The mediating role of organizational learning capability, Technological forecasting \& Social Change, pp. 1-14, 